\title{
Mental Health Outreach at Community Behavior Health Centers
}

\author{
Kristen Finley Sobota*, Joshua Blackwell, Brittany Dye, Kanika Kapoor, \\ Elizabeth Roediger, Micah Jared Sobota
}

Raabe College of Pharmacy, Ohio Northern University, Ada, USA
Email: *k-finley.1@onu.edu

Received 10 December 2013; revised 15 January 2014; accepted 22 January 2014

Copyright (C) 2014 by authors and Scientific Research Publishing Inc.

This work is licensed under the Creative Commons Attribution International License (CC BY). http://creativecommons.org/licenses/by/4.0/

(c) (i) Open Access

\begin{abstract}
Background: Major Depressive Disorder (MDD) is considered to be one of the most common incapacitating psychiatric diseases. A pharmacist interacting with patients has the potential to enhance compliance, ensure proper medication use, and monitor adverse effects that will ultimately improve patients' quality of care. Methods: The primary objectives of this study were to 1) assess individuals' knowledge of depression before and after a 30-minute educational intervention and 2) measure satisfaction with the program. The pre- and post-test consisted of 11 identical questions that assessed individuals' knowledge regarding depression. The survey consisted of four questions that rated program satisfaction. Results: Although 82 individuals participated in some aspect of the program, 56 individuals completed the program requirements and were included in the data analysis. Four hundred and eighty six of the total 616 (56 participants $\times 11$ questions) pre-test questions (79\%) were answered correctly at the beginning of the program. A total of 556 post-test questions $(90 \%)$ were answered correctly at the conclusion of the program, with an overall increase of 70 ( $p \leq 0.001)$ more correct answers. Correct responses to five questions were statistically significant for improved post-test scores: Over-the-counter or herbal medications will interfere with your medication ( $p=0.01$ ); certain foods can interfere with medications that affect mood $(p=0.01)$; it is safe to use multiple pharmacies to get your medications $(p=0.001)$; the main chemical of the brain that is not balanced in depression ( $p \leq 0.001)$; and the most common type of medication for depression ( $p \leq \mathbf{0 . 0 0 1}$ ). Overall, $95 \%$ of participants would recommend the program to a friend or family member. Conclusion: The data from this program supports that pharmacists can have a positive impact in the mental health field and satisfaction with such services in the community.
\end{abstract}

\section{Keywords}

Mental Health; Depression; Pharmacy Student; Pharmacist; Outreach

\footnotetext{
${ }^{*}$ Corresponding author.
} 


\section{Background}

Major Depressive Disorder (MDD) is considered to be one of the most common incapacitating psychiatric diseases [1] [2]. According to the Fifth Edition of the Diagnostic and Statistical Manual of Mental Disorders (DSM5), MDD is defined as a medical illness that affects an individual's thought process, emotions and behavior [3]. The diagnostic criteria is based on an impairment level and symptoms which include depressed mood; loss of interest; changes in weight, appetite, sleep, energy and activity; guilt or feelings of worthlessness; concentration issues; and can even be fatal with suicidal ideation [2]. Over the past 20 years, treatment for depression has drastically changed in regards to the types of treatment and systems involved [4]. Current MDD treatment includes a combination of behavioral, supportive and antidepressant therapy use [5].

The National Institute of Mental Health reports a 12 month prevalence of $6.7 \%$ of the US adult population. Further, breaking down the statistics with women as being $70 \%$ more likely than men to experience an episode of depression at some point during their lifetime [6]. Literature suggests that the average age during which an individual experiences a depressive disorder is between their early teenage years to their early thirties, and 3.3\% of patients between the ages of 13 - 18 experience an increasing impairing depressive disorder [6]. Caucasians of non-Hispanic descent are $40 \%$ more likely to experience depression some time during their lifetime than African Americans that do not have a Hispanic background [6]. When an individual lives with a comorbid condition or other health issue such as HIV/AIDS, cancer, or heart disease, the patient has a much higher prevalence of depression due to varying functional limitations [7]. Other risk factors of MDD include having a family history of depression, experiencing traumatic experiences during childhood, and alcohol or illicit drug use. MDD complications can result in suicidal ideation, self-mutilation, difficulties in maintaining relationships and employment, alcohol or substance abuse, and premature death from other conditions [8]. Apart from the above mentioned risk factors based on an individual's ethnicity, sex, age and comorbid conditions, the underserved population who lack health-care insurance also require increased attention from healthcare professionals due to underdiagnosis and undertreatment [9].

The treatment regimen tends to become both a financial as well as an emotional burden for the patients, their caregivers, and healthcare systems especially for those with potential risk factors. According to the Substance Abuse and Mental Health Services Administration, only 38\% of individuals with mental health issues (including MDD) have received appropriate services [10]. The Bureau of Labor Statistics states that access to mental health care is worse than any other medical services [11].

The large percentage of the disease state and lack of appropriate services clearly express the need for additional assistance from other healthcare professionals to help monitor and better serve patients. Pharmacist and pharmacy students are well equipped to fill the gap of inadequate treatment and increasing need for providers. A systematic review showed that pharmacists interventions in treating depressive disorders is highly favorable in regards to the cost: benefit ratio [12]. A pharmacist interacting with patients has the potential to enhance compliance, ensure proper medication use, and monitor adverse effects that will ultimately improve patients' quality of care [13]. Prior research further suggests that pharmacists have the ability to enhance other mental health services making patients more likely to be satisfied with their medications, less likely to stop therapies, and decrease the number of visits patients make to their primary care providers [14] [15]. It is evident that pharmacists and pharmacy students can have a significant impact on the profession by continuingly providing quality patient care, as well as educating patients in order to improve overall adherence rates.

\section{Study Objectives}

The primary objectives of this study were to 1) assess individuals' knowledge of depression before and after an educational intervention and 2) measure satisfaction with the educational program.

\section{Methods}

The research project was conducted at three locations in Lima, Ohio: Coleman Behavior Health, "Changing Seasons" at the YMCA, and the National Alliance on Mental Illness (NAMI) Ohio location. Coleman Behavioral Health is an outpatient center that sees indigent, adult patients and provides services including mental health, alcohol \& drug, and crisis interventions. Coleman also provides community support groups, supportive housing, criminal justice service, and outreach programs. On site psychiatrists, nurse practitioners, and pharmacists pro- 
vide care to these patients of Allen County. "Changing Seasons" is an outreach program that operates in the basement of the local YMCA Annex that helps those with chronic mental illness and those who are unemployed with support and social network. The YMCA Annex also serves as a shelter for homeless, single men and a collaborative center for many other non-profit organizations including Crossroads Crisis Center and Youth Life for Teens. NAMI Ohio offers classes, support, and education to consumers of mental health services and their families. Classes are taught by both licensed health care providers and trained family members of individuals suffering from mental illness and cover topics such as medication use, coping skills, brain basics, and advocacy.

The Ohio Northern University (ONU) Institutional Review Board (IRB) approved this study as an exempted research project. Potential study participants were eligible for inclusion if they were 18 years of age or older and had a documented mental illness or family member with mental illness. Individuals who attended the program but declined participation in the pre/post test and survey were excluded from the results. Individuals who only filled out the pre-test and left the educational program early were also excluded.

This study was conducted from September to November 2012. A total of four educational sessions took place at the three locations: two classes at Coleman, one at "Changing Seasons," and one at NAMI. Invitations were created and passed out in advance to individual patients and family members by health center and location staff. The intended study group was both patients primarily with depression and any individuals coping with mental illness amongst their family members. Although the study focused on depression education, those with other mental illnesses were not turned away from the study. The principal and co-investigators designed the pre/post test and survey (Appendices 1 and 2). The pre-test consisted of 11 questions that assessed patients' knowledge regarding depression, medication use, and lifestyle behaviors. The post-test administered at the conclusion of the program was identical to the pre-test. The survey consisted of four questions that rated overall program satisfaction and was administered immediately after the post-test. Please see Appendices 1 and 2 for how patients scored individual questions. After field testing of the pre/post test and survey, questions were modified slightly and the final version of the test and survey were used in the study.

A research consent form for group session was made available and approved by ONU IRB, and it was signed by all patients attending the sessions, regardless if they chose to fill out the test and survey. All four programs were run identical with the order of pre-test, educational intervention, post-test, and last the survey. The pre/ post test and survey were verbally read by a trained student pharmacist. Patients were numbered sequentially as they enrolled into the study. Pre/post tests and surveys were numbered to facilitate matching and allowed for the assessment of change in knowledge. These numbers were not linked to identifiable patient information. All test and survey data were entered into Microsoft Excel $2010^{\circledR}$ to calculate statistical analyses. Descriptive statistics were calculated for multiple parameters. The paired t-test was utilized to assess whether differences in pre-test results and post-test results were statistically significant.

The 30 minute educational intervention was presented by a pharmacist and trained pharmacy students in their fifth year of school ( 0 - 6 program). A professionally developed poster was used as a visual aid in the presentation and outlined the topics that were covered: depression in general, chemicals of the brain, treatment, and medications. Created by authors, the five feet by three feet poster was essential in content delivery and patient comprehension. A second pharmacist and other trained fifth year pharmacy students helped in the logistics of the program such as administering tests/surveys, answering any patient concerns, and passing out gift bags. Supplemental patient handouts from the National Institute of Mental Health were made available at the conclusion of the program if patients chose to take home. Dinner was provided at three of the programs, and gift bags which included a stress ball, healthy snacks, and a medication pill box were distributed to all patients in attendance. Patients were aware of incentives such as dinner, gift bags, and gift cards via invitations distributed by location staff members. In addition, two patients from each program were randomly selected to receive a \$25 gift card to a large retailer. Funds for the program were received through the ONU Summer Research Grant.

\section{Results}

Eighty-two individuals participated in some aspect of the program. Twenty-one individuals just participated in the education session and did not fill out the pre/post test. Five individuals participated in the education session and partially filled out the pre test only. Those 26 individuals were excluded from the final analysis due to incompletion of the entire intervention. Therefore, 56 individuals completed the program requirements and were included in the data analysis. Of those 56 individuals, $73 \%(n=41)$ identified themselves as patients with de- 
pression and 27\% ( $n=15)$ classified themselves as family members. Baseline demographics and characteristics are included in Table 1. The ethnicity of the study population was representative of Coleman Behavior Health, "Changing Seasons," and NAMI according to program reports.

Pre and Post Test: The pre and post test consisted of 11 identical questions that assessed patients' knowledge on depression in general. Of the 56 study participants, 486 of the total 616 (56 participants $\times 11$ questions) pretest questions (79\%) were answered correctly at the beginning of the program. A total of 556 post-test questions $(90 \%)$ were answered correctly at the conclusion of the program, with an overall increase of $70(p \leq 0.001)$ more correct answers. Table 2 shows the difference in the mean pre and post test scores for each individual question. Upon performing the paired t-test, several questions showed a statistically significant change from baseline ( $<<$ 0.05). Correct responses to five questions were significant for improved post-test scores: Over-the-counter or herbal medications will interfere with your medication $(p=0.01)$; certain foods can interfere with medications that affect mood ( $p=0.01)$; it is safe to use multiple pharmacies to get your medications $(p=0.001)$; the main chemical of the brain that is not balanced in depression ( $\mathrm{p} \leq 0.001$ ); and the most common type of medication for depression $(\mathrm{p} \leq 0.001)$. Other questions showed increased scores post-education but were not significant (Figure 1). No changes were demonstrated when data was analyzed comparatively for change in test scores between the three centers. Patients of Coleman Behavior Health are encouraged to attend support group sessions at "Changing Seasons" and NAMI, therefore the targeted population was similar.

Satisfaction Survey: Participants completed the survey immediately after the post-test. Satisfaction data demonstrated that $93 \%(n=52)$ of participants learned something new in regards to depression, while $57 \%(n=32)$ planned to follow up with a doctor. Fifty-seven percent $(n=32)$ rated the program very useful and $43 \%(n=24)$ rated it useful. Overall, 95\% $(n=53)$ would recommend the program to a friend or family member.

\section{Discussion}

By utilizing a survey before and after the educational presentation, we determined that the patients' level of knowledge regarding depression was improved in several areas. The greatest improvement from pre to post test scores included the two questions regarding the main chemical that is not balanced, as well as the main type of medication used for depression treatment. Initially, few patients answered these survey questions correctly, however, after the presentation there was a larger percentage of patients that selected the correct answer. It is important to consider the empowerment that a patient gains from understanding their overall health condition

Table 1. Characteristics of study participants $(\mathrm{N}=56)$.

\begin{tabular}{ccc}
\hline & Parameter & Number (\%) \\
\hline Sex & Male & $28(50)$ \\
& Female & $28(50)$ \\
White & $41(73)$ \\
Race/Ethnicity & African American & $11(19)$ \\
& Hispanic & $2(4)$ \\
Education & Asian & $0(0)$ \\
& Other & $2(4)$ \\
Reason for & College & $29(52)$ \\
Attendance & High-School Graduate & $26(46)$ \\
& Less than High-School & $1(2)$ \\
& Patient & $41(73)$ \\
& Family member & $15(27)$ \\
\hline
\end{tabular}


Table 2. Score summary by individual question $(\mathrm{N}=56)$.

\begin{tabular}{|c|c|c|c|c|c|}
\hline $\begin{array}{l}\text { Question } \\
\text { Number }\end{array}$ & Question & $\begin{array}{l}\text { Mean Pre-Test } \\
\text { Correct }\end{array}$ & $\begin{array}{l}\text { Mean Post-Test } \\
\text { Correct }\end{array}$ & $\begin{array}{c}\text { Change in } \\
\text { Mean Correct }\end{array}$ & p Value ${ }^{b}$ \\
\hline 1 & Is it okay to stop your medication if it makes you feel tired? & 0.91 & 0.95 & 0.04 & 0.32 \\
\hline 2 & $\begin{array}{l}\text { Over-the-counter or herbal medications will interfere with you } \\
\text { medication. }\end{array}$ & 0.84 & 0.98 & 0.14 & $0.01^{*}$ \\
\hline 3 & $\begin{array}{l}\text { If you forgot to take your medication, it is safe to take } 2 \text { pills at } \\
\text { once and then restart your medication. }\end{array}$ & 0.96 & 0.96 & 0.00 & 1.0 \\
\hline 4 & Caffeine will not affect your mood. & 0.88 & 0.77 & -0.11 & 0.08 \\
\hline 5 & Certain foods can interfere with medications that affect mood. & 0.77 & 0.93 & 0.16 & $0.01^{*}$ \\
\hline 6 & Will alcohol affect your mood? & 0.95 & 0.98 & 0.03 & 0.16 \\
\hline 7 & Marijuana or other illicit drugs do affect mood. & 0.93 & 0.98 & 0.05 & 0.08 \\
\hline 8 & $\begin{array}{l}\text { If your mood has been fine for the past } 2 \text { years, it is safe to stop } \\
\text { taking your medication before your next doctor appointment. }\end{array}$ & 0.95 & 0.98 & 0.03 & 0.32 \\
\hline 9 & $\begin{array}{l}\text { The main chemical of the brain that is not balanced in depres- } \\
\text { sion is: }\end{array}$ & 0.43 & 0.80 & 0.37 & $<0.001^{*}$ \\
\hline 10 & The most common type of medication for depression is: & 0.38 & 0.68 & 0.3 & $<0.001^{*}$ \\
\hline 11 & $\begin{array}{l}\text { It is safe to use multiple pharmacies to get your medications } \\
\text { (using one pharmacy for free medication and another pharmacy } \\
\text { for } \$ 4 \text { medications). }\end{array}$ & 0.70 & 0.91 & 0.21 & $0.001^{*}$ \\
\hline
\end{tabular}

${ }^{\mathrm{a} C a l c u l a t e d ~ b y ~ m e a n ~ p o s t-t e s t ~ c o r r e c t ~ m i n u s ~ m e a n ~ p r e-t e s t ~ c o r r e c t ; ~}{ }^{\mathrm{b}}$ Calculated by a paired t-test on Excel 2010; asterisk $\left({ }^{*}\right)$ indicates statistical significance.

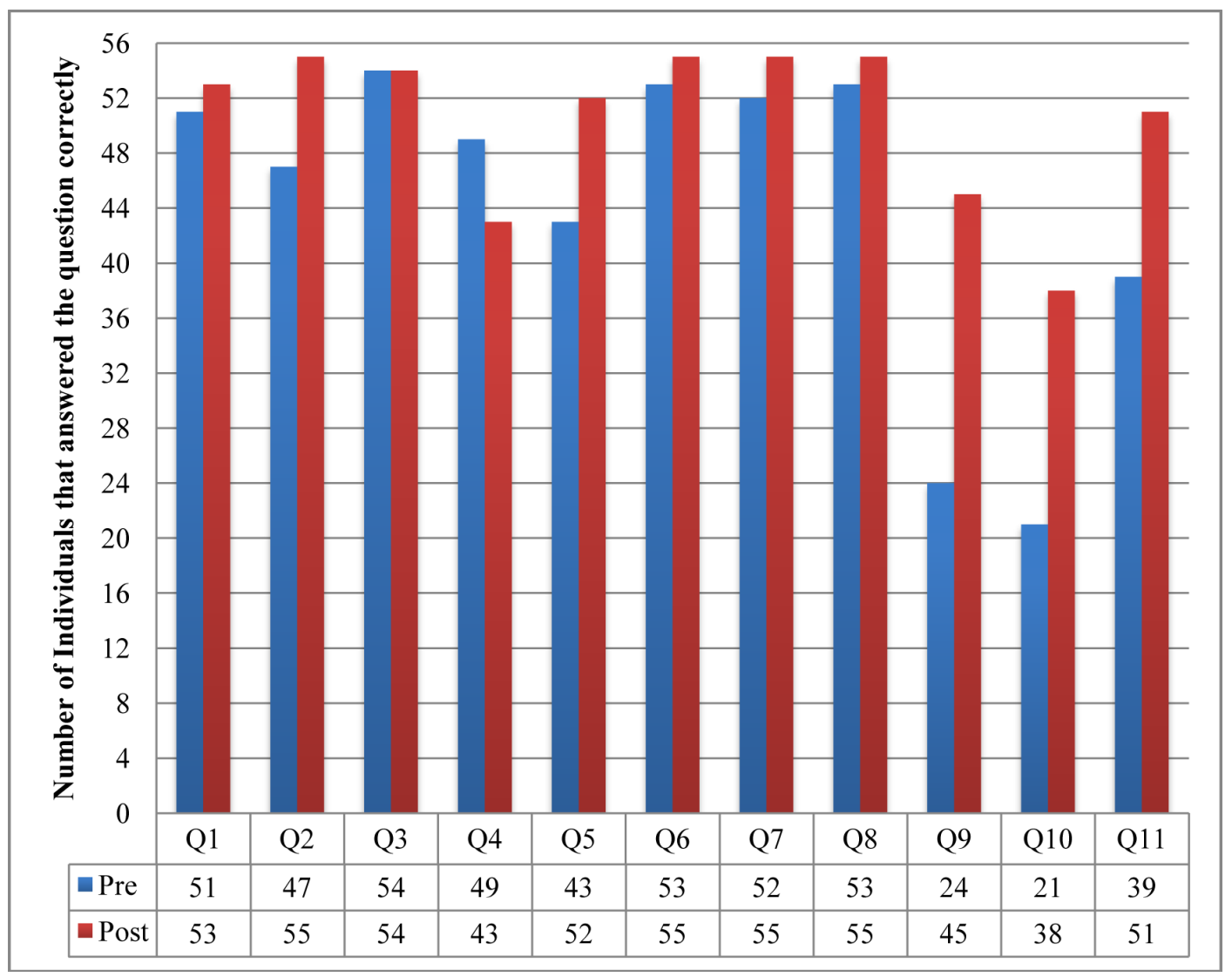

Figure 1. Pre- vs post-test comparison of survey questions correctly answered. 
and our role as pharmacy providers in educating patients.

Considering the lack of literature on similar studies in different settings, the importance of this research is clear that pharmacists and pharmacy students play a vital role as patient educators in the mental health field. The data from this outreach program supports that pharmacists and student pharmacists can have a positive impact in the area of mental health and satisfaction with such services in various community settings. There is often a low availability of mental health services, particularly to indigent populations in the United States. This leaves patients with a lack of convenient, reliable, and affordable health care and education. One unique aspect of depression is the fact that nearly any co-morbidity may lead to, or increase the risk of its diagnosis [16] [17]. In fact, depression and related mental health diseases are more common in those with co-morbid chronic diseases, such as hypertension, diabetes, and obesity [16] [17]. Pharmacists often play an integral role in disease state and medication therapy management, and therefore can help resolve the barriers of receiving mental health care. By increasing opportunities to receive education and counseling, this would help fulfill the patients' needs for increased quality of care.

One strength of this outreach program was that the same two pharmacists and four pharmacy students were involved in all four events. Everyone's role during the programs (reading pre/post test, delivering the education, etc.) remained the same each time, which helped to ensure consistency in program delivery. Another strength included program delivery at three different locations in Lima, Oh. Utilizing a health care clinic and two different support groups, we were able to capture a diverse participant population. This unique outreach service can be duplicated by other professional pharmacy organizations and incorporated into Introductory or Advanced Pharmacy Practice Experiences (IPPE or APPE). ONU's Student National Pharmaceutical Association (SNPhA) chapter was responsible for the creation and implementation of this program for various community settings of Allen County. Participation in patient care projects at various community sites such as health care clinics and support groups allows pharmacy students to be exposed to a more diverse patient population and their family members.

Limitations to this study include non-validated instruments therefore the results should be viewed as preliminary. Although other health care professionals have never used this test and survey, the questions captured the study participants' assessment of depression knowledge. The post-test and survey was administered directly after the educational session, and as a result participant retention is unknown. The design of the study did not allow for the evaluation of long-term retention of knowledge. One out of the 11 test questions scored a lower post test score compared to pre test scores: caffeine will not affect your mood. Although the decrease was not statistically significant, patients may not have understood the question or there may have been a communication error during the presentation. Some patients had previously been on depression medications and had multiple mental health diagnoses; therefore they may have had higher baseline knowledge than then general population. This study included patients and family members with any mental illness, yet the educational piece focused only on MDD. The authors feel this may have affected the implementation of the project because of the higher percentage of pre-test scores. Also, this project took place at two support groups; therefore patients may have been exposed to this information in other classes. Finally, another limitation to the study design is the lack of a control group. Future studies may conduct educational sessions with patients who have just been newly diagnosed with depression or initiated a new medication. The inclusion of a control group with no educational intervention would also strengthen the study.

\section{Conclusion}

Use of a depression pre- and post-test provided pharmacists and pharmacy students an opportunity to assess patients' knowledge associated with mental health, medication use, and lifestyle behaviors. With the low availability of mental health services available in the United States, pharmacists and pharmacy students play a vital role in education and medication management in this area. Although this was a small study and outreach project, the results were promising and can build on the current example by exploring the long-term effect of pharmacist interventions and depression.

\section{Disclosure}

The authors declare no conflicts of interest or financial interests in any product or service mentioned in this article, including grants, employment, gifts, stock holdings, or honoraria. 


\section{Funding}

Ohio Northern University Faculty Development Summer Research Grant.

\section{Previous Presentations}

Ohio Pharmacists Association Annual Meeting, April 12-14, 2013, Columbus, Ohio and the SNPhA Annual Meeting July 26-29, 2013, New Orleans, Louisiana.

\section{Acknowledgements}

To the staff at Coleman Behavior Health, "Changing Seasons” YMCA Annex, and NAMI (all Lima, Ohio locations) for enrollment of study participants and support throughout programs; the Ohio Northern University Student National Pharmaceutical Association (SNPhA) Chapter for assistance in program implementation.

\section{References}

[1] Kupfer, D.J., Ellen, F. and Phillips, M. (2012) Major Depressive Disorder: New Clinical, Neurobiological, and Treatment Perspectives. Lancet, 379, 1045-1055. http://dx.doi.org/10.1016/S0140-6736(11)60602-8

[2] Klein, D.N., Glenn, C.R., Kosty, D.B., Seeley, J.R., Rohde, P. and Lewinsohn, P.M. (2013) Predictors of First Lifetime Onset of Major Depressive Disorder in Young Adulthood. Journal of Abnormal Psychology, 122, 1-6. http://dx.doi.org/10.1037/a0029567

[3] American Psychiatric Association. (2013) Major Depressive Disorder and the "Bereavement Exclusion”. American Psychiatric Press, Inc., Washington DC. http://www.dsm5.org

[4] Wang, P.S., Berglund, P. and Kessler, R.C. (2000) Recent Care of Common Mental Disorders in the United States Prevalence and Conformance with Evidence-Based Recommendations. Journal of General Internal Medicine, 15, 284292. http://dx.doi.org/10.1046/j.1525-1497.2000.9908044.x

[5] Blumenthal, J.A., Babyak, M.A., Doraiswamy, P.M., Watkins, L., Hoffman, B.M., Barbour, K.A., et al. (2007) Exercise and Pharmacotherapy in the Treatment of Major Depressive Disorder. Psychosomatic Medicine, 69, 587-596. http://dx.doi.org/10.1097/PSY.0b013e318148c19a

[6] National Institute of Mental Health (2013) Depression. Bethesda. http://www.nimh.nih.gov/health/topics/depression/index.shtml\#part4 http://www.nimh.nih.gov/statistics/1mdd_adult.shtml

[7] Toukhsati, S. and Hare, D. (2013) Detecting and Managing Depression in Patients with Cardiac Disease. Cardiology Today, 3, 27-30.

[8] Depressive Disorders. The Merck Manuals: The Merck Manual for Healthcare Professionals. http://www.merckmanuals.com/professional/psychiatric_disorders/mood_disorders/depressive_disorders.html\#top

[9] Starks, J.M., Poulin, C.C. and Kisley, S.R. (2005) Unmet Need for the Treatment of Depression in Atlantic Canada. Canadian Journal of Psychiatry, 50, 580-590.

[10] Substance Abuse and Mental Health Services Administration (2012) Results from the 2011 National Survey on Drug Use and Health: Mental Health Findings. NSDUH Series H-45, Substance Abuse and Mental Health Services Administration, Rockville.

[11] United States Department of Labor: Bureau of Labor Statistics. www.bls.gov/ncs/ebs/

[12] Finley, P.R., Crismon, M.L. and Rush, A.J. (2003) Evaluating the Impact of Pharmacists in Mental Health: A Systematic Review. Pharmacotherapy, 23, 1634-1644.

[13] Capoccia, K.L., Boudreau, D.M., Blough, D.K., Ellsworth, A.J., Clark, D.R., Stevens, N.G., et al. (2004) Randomized Trial of Pharmacist Interventions to Improve Depression Care and Outcomes in Primary Care. American Journal of Health-System Pharmacy, 61, 364-372.

[14] Crockett, J., Taylor, S., Grabham, A. and Stanford, P. (2006) Patient Outcomes Following an Intervention Involving Community Pharmacists in the Management of Depression. Australian Journal of Rural Health, 14, 263-269. http://dx.doi.org/10.1111/j.1440-1584.2006.00827.x

[15] Gilbody, S., Whitty, P., Grimshaw, J. and Thomas, R. (2003) Educational and Organizational Interventions to Improve the Management of Depression in Primary Care. Journal of the American Medical Association, 289, 3145-3151. http://dx.doi.org/10.1001/jama.289.23.3145

[16] Strine, T.W., Mokdad, A.H., Balluz, L.S., et al. (2008) Depression and Anxiety in the United States: Findings from the 
2006 Behavioral Risk Factor Surveillance System. Psychiatric Services, 59, 1383-1390. http://dx.doi.org/10.1176/appi.ps.59.12.1383

[17] Chapman, D.P., Perry, G.S. and Strine, T.W. (2005) The Vital Link between Chronic Disease and Depressive Disorders. Preventing Chronic Disease, 2, A14. 


\section{Appendix 1: Pre and Post Test}

1) Is it ok to stop your medication if it makes you feel tired?
a. Yes
b. No

2) Over-the-Counter or herbal medications will interfere with your medication.
a. True
b. False

3) If you forgot to take your medication, it is safe to take 2 pills at once and then restart your medication.
a. True
b. False

4) Caffeine will not affect your mood.
a. True
b. False

5) Certain foods can interfere with medications that affect mood.
a. True
b. False

6) Will alcohol affect your mood?
a. Yes
b. No

7) Marijuana or other illicit drugs do affect mood.
a. True
b. False

8) If your mood has been fine for the past 2 years, it is safe to stop taking your medication before your next doctor appointment.
a. True
b. False

9) The main chemical of the brain that is not balanced in depression is:
a. Norepinephrine
b. Serotonin
c. GABA
d. Dopamine

10) The most common type of medication for depression is:
a. MonoAmine Oxidase Inhibitor (MAO-I)
b. Tricyclic Antidepressant (TCA)
c. Selective Serotonin Reuptake Inhibitor (SSRI)
d. Atypical Antipsychotic (AAP)

11) It is safe to use multiple pharmacies to get your medications (using one pharmacy for free medication and another pharmacy for $\$ 4$ medications).
a. True
b. False

\section{Appendix 2: Post Survey}

1) Did you learn something new in regards to depression from today’s program?
a. No
b. Yes

2) Do you plan to talk to a doctor to follow up on what you learned today? Please choose one answer.
a. No
b. Yes
c. I don't know or I'm not sure

3) How useful was today's program for increasing your understanding for depression and the medications used to treat depression. Please choose one answer.
a. Not useful 

b. Somewhat useful
c. Useful
d. Very useful

4) Would you recommend this program to a friend or family member?
a. No
b. Yes 